\title{
Article \\ Efficiency Enhancement of GaAs Single-Junction Solar Cell by Nanotextured Window Layer
}

\author{
Chae-Won Kim ${ }^{1,2}$ (D) Gwang-Yeol Park ${ }^{1}$, Jae-Cheol Shin ${ }^{2}$ and Hyo-Jin Kim ${ }^{1, *}$ \\ 1 Optoelectric Convergence Research Center, Korea Photonics Technology Institute, Gwangju 61007, Korea; \\ aria101402@kopti.re.kr (C.-W.K.); gypark19@kopti.re.kr (G.-Y.P.) \\ 2 Nano-Optoelectronic Device Laboratory, Department of Physics, Yeungnam University, Gyeongsang 38541, \\ Korea; jcshin@yu.ac.kr \\ * Correspondence: hjk@kopti.re.kr
}

Citation: Kim, C.-W.; Park, G.-Y.; Shin, J.-C.; Kim, H.-J. Efficiency Enhancement of GaAs Single-Junction Solar Cell by Nanotextured Window Layer. Appl. Sci. 2022, 12, 601. https://doi.org/ 10.3390/app12020601

Academic Editors: Eun-Chel Cho and Hongsub Jee

Received: 5 December 2021

Accepted: 6 January 2022

Published: 8 January 2022

Publisher's Note: MDPI stays neutral with regard to jurisdictional claims in published maps and institutional affiliations.

Copyright: () 2022 by the authors. Licensee MDPI, Basel, Switzerland. This article is an open access article distributed under the terms and conditions of the Creative Commons Attribution (CC BY) license (https:// creativecommons.org/licenses/by/ $4.0 /)$.

\begin{abstract}
In order to improve efficiency of flexible III-V semiconductor multi-junction solar cells, it is important to enhance the current density for efficiency improvement and to attain an even efficiency of solar cells on a curved surface. In this study, the nanotextured InAlP window layer of a GaAs single-junction solar cell was employed to suppress reflectance in broad range. The nanotextured surface affects the reflectance suppression with the broad spectrum of wavelength, which causes it to increase the current density and efficiency of the GaAs single-junction solar cell and alleviate the efficiency drop at the high incident angle of the light source. Those results show the potential of the effectively suppressed reflectance of multi-junction solar cells and even performance of solar cells attached on a curved surface.
\end{abstract}

Keywords: III-V; nanotextured solar cell; omnidirectional effect; GaAs

\section{Introduction}

Flexible III-V semiconductor solar cells (SCs) are advantageous materials with rare heat loss compared to Si SCs. This is because GaAs SCs have the features of a physically direct bandgap and lattice match properties, which means that carriers pass SCs without recombination. Therefore, III-V semiconductor SCs show a high efficiency even with a thin film. In solar cell applications, the photocurrent conversion efficiency ( $\eta$ ) of GaAs SCs predicted by theoretical calculations or demonstrated by actual fabrication has been found to be higher than that of silicon [1-6]. A higher $\eta$ with thin thickness is an advantageous factor for flexible SCs applied to a wearable or portable device [7-12]. The issue of a flexible SC attached on a curved surface is $\eta$ degradation compared with the planar SC because of the tilted incident angle of the light source. In order to alleviate the $\eta$ loss, various techniques have been developed to improve the performance such as depositing the planar anti-reflection coated (ARC) film and three-dimensional surface texturing, such as texturing the window surface of the SC and texturing the oxide layer covering the SC [13-15].

When a light source is irradiated on the nanoscale textured surface, light in a wide range of $\lambda$ is evenly scattered on the nanotextured (NT) layer, where the refractive index is gradually changed by the moth-eye effect $[16,17]$. It leads to higher light transmittance and longer optical path length, which improves the low short-circuit current density (JSC) and $\eta$ [18-21]. The micro-hole structured InAlP window surface InGaP single-junction (1J) SC was designed by Millennium Communication Co., Ltd. [14]. This textured SC improved the external quantum efficiency (EQE), JSC, and $\eta$ rather than an SC with a bare surface. However, $\eta$ with varying incident angle $(\theta)$ of light source was not investigated, so it is not possible to find the omnidirectional effect of textured SCs. The ZnO nanoneedle layer covering the InGaP/GaAs/Ge triple-junction SC was designed by KAUST [15]. The AZO nanoneedle-shaped SC reduce the reflectance and enhance the EQE, $\mathrm{J}_{S C}$, and $\eta$ such as a previous study. In addition, the result of $\eta$ with varying $\theta$ was also measured, which 
showed that textured SCs have the feature of the omnidirectional effect compared to the planar SC with a bare surface. However, the comparison of performance between NT SC and ARC SC was not provided, although ARC SCs actually have been utilized more in commercials and industries than SCs with the bare surface. According to the studying result for solar cell with a nanotextured window layer in the other group [14,15], these papers have only shown the superiority of nanostructures by comparing solar cells with nanostructures and the bare solar cells excluding ARC. This study is different from comparing the solar cell with the ARC thin film layer used as a practical fabric with the solar cell with the nanostructure of the InAlP window layer. Additionally, it is refreshing to investigate the efficiency change with respect to the angle of incidence.

In this study, the NT window layer of inverted epi-grown GaAs 1J SC was fabricated by using polystyrene (PS) beads. The measured performance of fabricated NT SC was compared to that of the planar ARC SC. Furthermore, $\eta$ with various $\theta$ s of the light source was examined and compared.

\section{Materials and Methods}

The inverted GaAs 1J SCs were grown on Si-doped (100) GaAs substrates oriented $2{ }^{\circ} \mathrm{C}$ off [111], through a metalorganic chemical vapor deposition (AIX200/4 RF, AIXTRON Inc., Cambridge, UK). Trimethylgallium, trimethylindium, and trimethylaluminum were employed as a group III source. Arsine and phosphine were employed as a group V source. Diethylzinc and disilane were employed as the p-dopant and n-dopant, respectively. The area of the fabricated SCs was $0.27 \mathrm{~cm}^{2}$. Commonly, the GaAs 1J SC was composed of a $\mathrm{n}^{+}$-GaAs Ohmic layer, $\mathrm{n}$-InAlP window, n-GaAs emitter, p-pressure of $30 \mathrm{mTorr}$, and radio frequency power of $250 \mathrm{~W}$ for etching $\mathrm{SiO}_{2}$. The GaAs contact layer and InAlP window layer was etched using $\mathrm{HBr}$ and Ar gas by an inductive co GaAs base, and p-InGaP back surface field (BSF) layer as shown in Figure 1. The doping concentration and thickness of each layer were grown under the following conditions: a $0.3 \mu \mathrm{m}$ p-type GaAs contact layer with a hole concentration of $1.49 \times 10^{19} \mathrm{~cm}^{-3}$ and a GaAs bottom cell consisting of a $0.3 \mu \mathrm{m}$ p-type GaAs contact layer with a hole concentration of $1.49 \times 10^{19} \mathrm{~cm}^{-3}$, a $100 \mathrm{~nm}$ thick $3.94 \times 10^{18} \mathrm{~cm}^{-3}$ p-type $\operatorname{In}_{0.51} \mathrm{Ga}_{0.49} \mathrm{P}$ back surface field (BSF) layer, a $3.3 \mu \mathrm{m}$ thick $1.23 \times 10^{17} \mathrm{~cm}^{-3}$ p-type GaAs base layer, a $100 \mathrm{~nm}$ thick $2.00 \mathrm{E} 18 \mathrm{~cm}^{-3} \mathrm{n}$ type GaAs emitter layer, a 4.15E17 $\mathrm{cm}^{-3}$ n-type InAlP window layer, and a $0.3 \mu \mathrm{m}$ thick $8.5 \times 10^{19} \mathrm{~cm}^{-3} \mathrm{n}^{+}$-type GaAs contact layer in succession. The doping concentrations of each layer were investigated by Hall measurement. The InAlP window layer with a thickness of $\sim 500 \mathrm{~nm}$ was grown. Then, $150 \mathrm{~nm}$ of $\mathrm{SiO}_{2}$ was deposited on $\mathrm{GaAs} 1 \mathrm{~J}$ SC by a plasma-enhanced chemical vapor deposition (PECVD) system (SLR-730, Oerlikon Corp., Freienbach, Switzerland). A monolayer of PS beads that floats on DI-water (diameter of $\sim 400 \mathrm{~nm}, 4 \% w / v$ in DI-water, purchased from Thermo Fisher Scientific Corp., Waltham, $\mathrm{MA}, \mathrm{USA}$ ) was scooped by $\mathrm{SiO}_{2}$-deposited GaAs $1 \mathrm{~J} \mathrm{SC}$ and dried naturally. The diameter of dried PS beads was adjusted to $\sim 300 \mathrm{~nm}$ by a reactive ion etching (RIE) system (FABstarRIE, Titiel Corp., London, UK) using $\mathrm{O}_{2}$ gas. The etched PS beads monolayer transferred the pattern to the $\mathrm{SiO}_{2}$ layer by etching $\mathrm{SiO}_{2}$ using $\mathrm{CF}_{4}$ gas by $\mathrm{RIE}$, which is utilized as a mask layer. PS beads were eliminated by RIE using $\mathrm{O}_{2}$ gas after carrying out fabricating the $\mathrm{SiO}_{2}$ mask layer by RIE. RIE was operated at the working pressure of $60 \mathrm{mTorr}$ and the radio frequency power of $80 \mathrm{~W}$ for etching PS beads and the working coupled plasma (ICP) system (SLR-770, Oerlikon Corp.). ICP was operated at the working pressure of $10 \mathrm{mTorr}$ and the radio frequency power of $150 \mathrm{~W}$ for etching the GaAs/InAlP layer. The mask layer was removed by immersing SC in BOE for $\sim 5 \mathrm{~s}$. For exposing the NT InAlP window layer, the GaAs contact layer was etched by dipping in citric acid solution for $\sim 60 \mathrm{~s}$. The rough surface of NT InAlP layer was polished by dipping in the solution of $\mathrm{HCl}: \mathrm{H}_{2} \mathrm{O}=1: 5$ for $1 \mathrm{~s}$. Then, $105 \mathrm{~nm}$ of $\mathrm{SiN}_{\mathrm{x}}$ was deposited on the polished NT InAlP widow layer as a passivation layer. The fabricated sequence of texturing is illustrated in Figure 2, and the schematic structure of GaAs 1J NT SC is shown in Figure 1. 


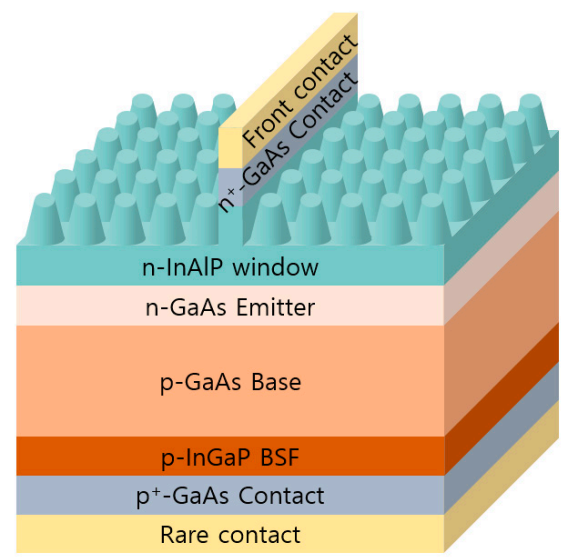

Figure 1. Schematic structure of the NT InAlP window layer GaAs 1J SC.
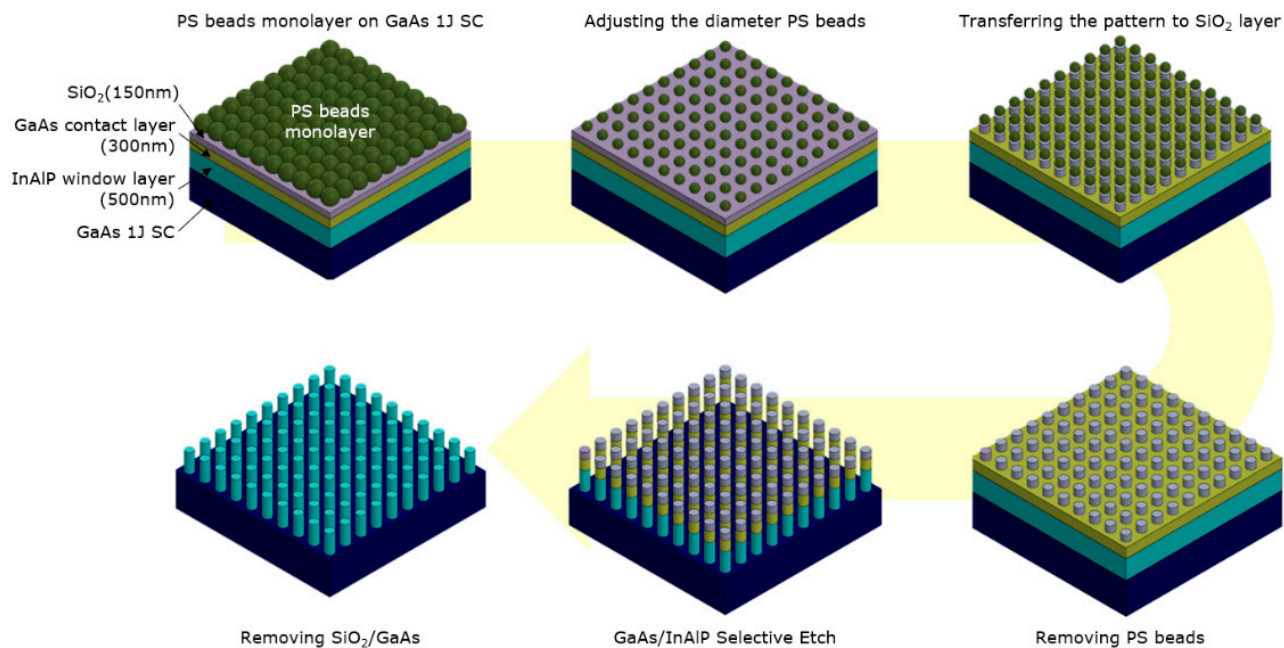

Figure 2. Schematic illustration of sequence of the nanotexturing process.

In addition, in order to compare performances, two types of surface conditions of the GaAs 1J SCs were prepared with the $\sim 30 \mathrm{~nm}$ of the InAlP window layer. One is an GaAs 1J SC with a bare surface, i.e., the InAlP window layer of the SC was exposed. The other one is the GaAs 1J SC with the planar $80 \mathrm{~nm}$ of $\mathrm{SiN}_{\mathrm{X}}$ as the ARC layer deposited by an ion beamassisted deposition system (IBAD System, Infovion Inc., Richardson, TX, USA), which is a conventional anti-reflection method using a multi-layer, thin film, anti-reflection coating with various materials and thicknesses [13]. With the intention of investigating devices with different surface conditions, enlarged images of surfaces at high magnification were studied through a scanning electron microscope (SEM) (S-4700, Hitachi, Tokyo, Japan), the light reflectance was studied using the UV-VIS reflection measurement module (B0086703, Perkin Elmer Corp., Waltham, MA, USA), current density voltage (J-V) characteristics under 1 sun AM $1.5 \mathrm{G}\left(100 \mathrm{~mW} / \mathrm{cm}^{2}\right)$ illuminance by the solar simulator (XIL-01B50KP, Technox Inc., Chicago, IL, USA), and EQE by the spectral response measuring system (S9230-MJ5, Soma Optics Ltd., Tokyo, Japan). Furthermore, $\eta$ with various $\theta$ s between the surface normal and the incident light beam from $0^{\circ} \mathrm{C}$ to $70^{\circ} \mathrm{C}$ at intervals of $10^{\circ} \mathrm{C}$ were compared with different surface conditions so as to examine the omnidirectional effect. The distance between light source and optic acquisition of devices was kept constant while $\theta$ changed. All measurements were carried out at room temperature.

\section{Results}

The monolayer of naturally dried PS beads covered the planar surface as shown in Figure 3 a. To make a $\mathrm{SiO}_{2}$ layer with a diameter of about $300 \mathrm{~nm}$, PS beads were dry etched 
by RIE to have a suitable diameter. Figure $3 b$ shows the shape in which the diameter of the $400 \mathrm{~nm}$ PS bead was changed to about $300 \mathrm{~nm}$ by RIE etching after carrying out fabricating the $\mathrm{SiO}_{2}$ mask layer by RIE. The GaAs contact layer and InAlP window layer were etched using $\mathrm{HBr}$ and $\mathrm{Ar}$ gas by ICP. Figure $3 \mathrm{c}$, d shows the SEM cross-sectional image and $45^{\circ} \mathrm{C}$ tilted surface of the NT InAlP window layer, respectively. The NT InAlP window layer was applied to the GaAs 1J SC.

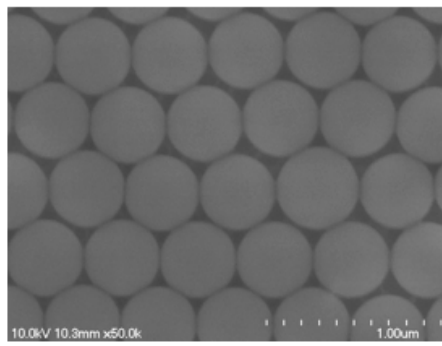

(a)

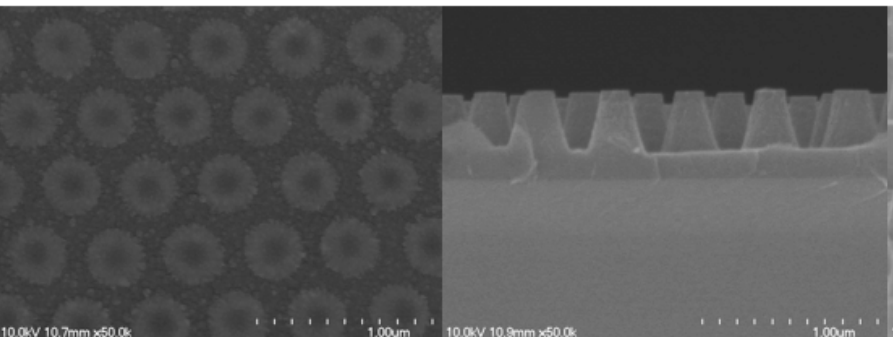

(b) (c)

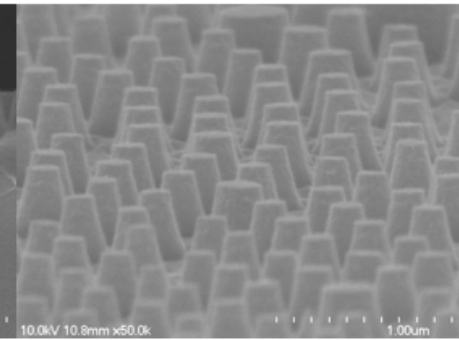

(d)

Figure 3. SEM images: Top view of (a) PS beads monolayer on GaAs substrate and (b) PS beads, whose diameter of about $350 \mathrm{~nm}$ was adjusted by RIE using $\mathrm{O}_{2}$ gas, (c) a profile, and (d) tilted images of the NT InAlP window layer.

Figure 4 shows the spectra of specular reflectance measured on GaAs substrates with different surface conditions: the bare GaAs surface, the planar ARC surface, and the threedimensional NT InAlP surface. Both ARC and NT surfaces exhibited suppressed reflectance compared to the bare surface. The planar ARC layer suppressed the reflectance through destructive interference effects caused by out-of-phase reflected waves of the light from interfaces between the bilayers of ARC and SC. The NT layer reduced the reflectance by gradually changing the refractive index by the moth-eye effect $[16,17]$. The noticeable distinction of the plotted reflectance- $\lambda$ curves between the ARC and NT surfaces is the difference of $\lambda$ range, where the reflectance is effectively suppressed compared with the specular, reflected, bare GaAs surface. The NT surface suppressed the reflection at a wide $\lambda$ range from $550 \mathrm{~nm}$ to $1200 \mathrm{~nm}$ evenly, which covers the whole range of GaAs 1J SCs enough. The suppressed reflectance by the NT surface mainly originates in the nanoscale threedimensional layer. Since the geometric features of the factor NT surface exhibit the most index grading from air to the device, a remarkably low reflectance is achieved. Whereas the planar ARC surface suppresses the reflectance at a partial $\lambda$ range, approximately from $\sim 750 \mathrm{~nm}$ to $\sim 1000 \mathrm{~nm}$, and consequently reveals a limitation of the planar ARC layer. As a result, the broad $\lambda$ range of reflectance is more considerably reduced by the NT surface than the planar ARC surface.

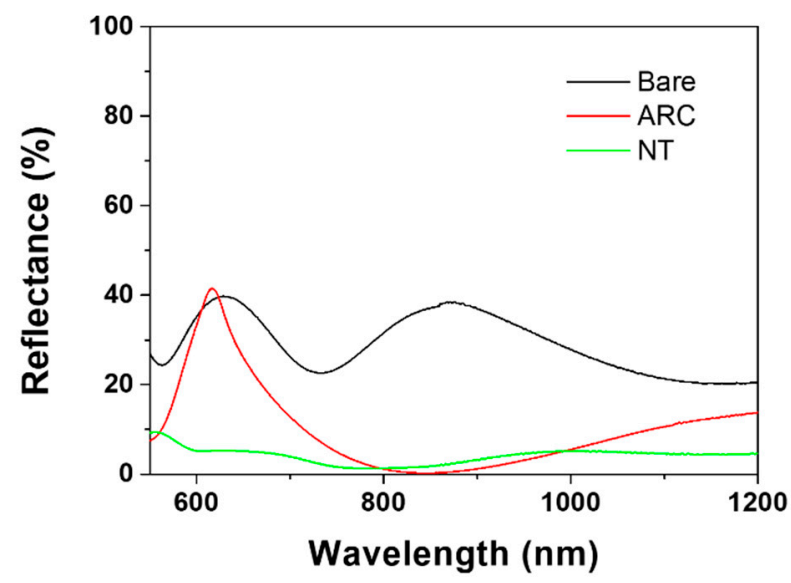

Figure 4. Surface reflectance for the bare surface SC, SC with $\mathrm{SiN}_{\mathrm{x}} \mathrm{ARC}$, and InAlP NT surface. 
The effects of the surfaces with different conditions on the nanostructure are mostly smaller than the studied wavelengths; $\lambda$ of the incident light regards the nanostructure as an effective medium, whose effective refractive index falls off the InAlP towards the bottom, significantly reducing the undesired reflectance through destructive interferences among the beams reflected from different depths into the nanostructure $[17,19,22]$. As the effective medium provides a graded refractive index between the air and InAlP because of the increased space filling, the photocurrent generation by each SC was examined from the EQE spectra, as shown in Figure 5. The EQE spectra reveal that both ARC and NT surfaces benefit the carrier generation of GaAs 1J SC and elongate the diffusion length [23]. However, there is no significant difference of the EQE spectra between the ARC and the NT SC as plotted in Figure 5, whereas the reflectance spectra between the ARC and NT surfaces, as shown in Figure 4, present a distinct difference.

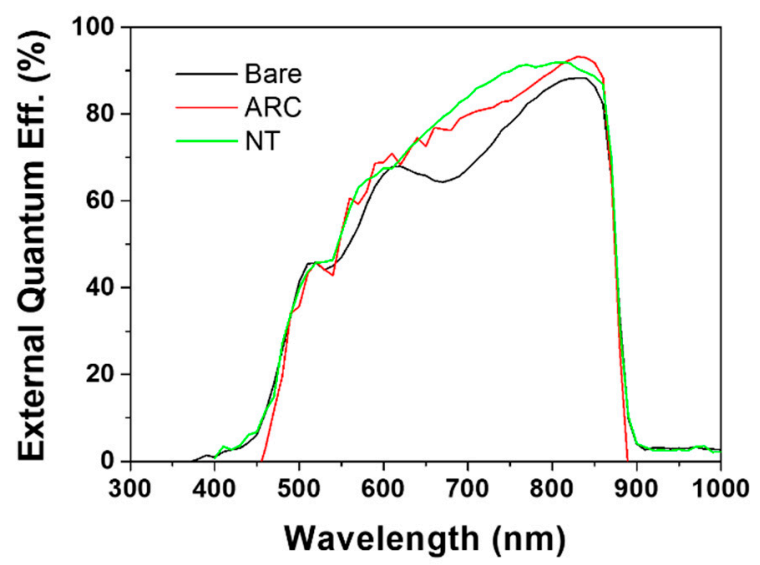

Figure 5. EQE for the bare surface SC, SC with $\mathrm{SiN}_{\mathrm{x}} \mathrm{ARC}$, and InAIP NT surface.

Enhanced EQE affects current density (J) improvement, as in Equation (1):

$$
E Q E=\frac{I / e}{P_{0} / h c}=\frac{J A / e}{P_{0} / h c}
$$

where $I$ is the current, $e$ is the charge of one electron, $P_{0}$ is the total power of photons, $h$ is the Planck constant, $c$ is the speed of light, and $A$ is the surface area of the device receiving the light. As a result, the improved J spectra of the ARC and NT SC compared to the bare surface SC was represented, as shown in Figure 6. The EQE of the ARC and NT SC increased similarly from the bare surface SC with no conspicuous offset between each other as shown in Figure 5; the J-V curves as plotted in Figure 6 reveal that the J of the ARC and NT SC increased with no conspicuous offset from the bare surface SC.

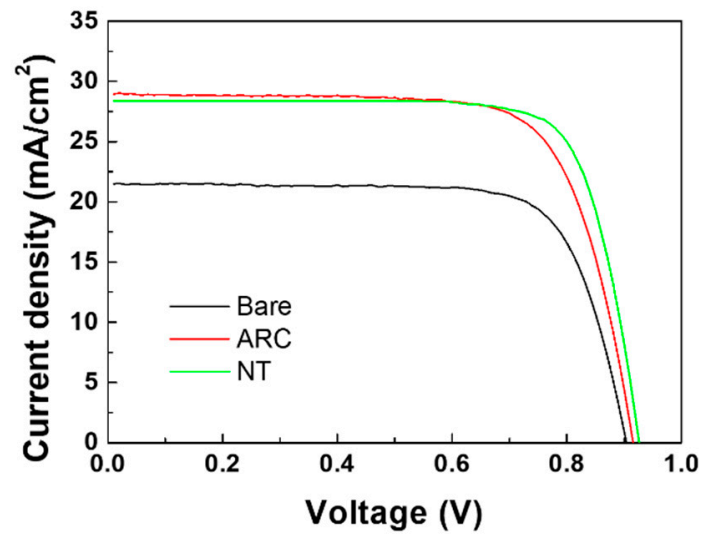

Figure 6. J-V curves for the bare surface SC, SC with SiNx ARC, and InAlP NT surface. 
The specific measured device parameters from the J-V curves, as shown in Figure 6, are summarized in Table 1. In order to investigate the effect of the NT surface on GaAs 1J SC, the photovoltaic J-V characteristics were measured. As the bare surface SC for reference, the improved J was the main factor to increase $\eta$. As shown in Figure 4, the NT surface has a lower reflectance in a wider absorption wavelength range than that of the ARC surface, but the reflectance of the ARC surface is less in the wavelength band near the GaAs energy bandgap. As shown in Figure 5, the EQE of NT solar cells is greater than that of ARC solar cells, but the EQE of ARC solar cells is larger in the wavelength band near the GaAs energy bandgap. As a result of the reflectance and quantum efficiency, the current density of the NT solar cell is slightly lower than that of the ARC solar cell, but the open circuit voltage is slightly increased.

Table 1. Voc, Jsc, fill factor (FF), and $\eta$ for J-V curves as shown in Figure 6.

\begin{tabular}{ccccc}
\hline & $\mathrm{V}_{\text {OC }}(\mathbf{V})$ & $\mathrm{J}_{\text {SC }}\left(\mathbf{m A} / \mathbf{c m}^{\mathbf{2}}\right)$ & FF & $\eta \mathbf{~ ( \% )}$ \\
\hline Bare & 0.91 & 21.50 & 0.71 & 13.81 \\
ARC & 0.92 & 28.94 & 0.72 & 19.07 \\
NT & 0.93 & 28.40 & 0.74 & 19.44 \\
\hline
\end{tabular}

As shown in Figure 7, efficiencies were acquired with varying $\theta$ from $0{ }^{\circ} \mathrm{C}$ to $70{ }^{\circ} \mathrm{C}$ at intervals of $10^{\circ} \mathrm{C}$. The $\eta$ of the NT SC is apparently higher than the $\eta$ of the ARC SC at all ranges of $\theta$. The $\eta$ of the NT SC from $0{ }^{\circ} \mathrm{C}$ to $20^{\circ} \mathrm{C}$ was almost preserved and the gaps of $\eta$ between the NT and ARC SC were gradually wider from $50{ }^{\circ} \mathrm{C}$ to $70{ }^{\circ} \mathrm{C}$. The $\eta$ at $70{ }^{\circ} \mathrm{C}$ of the NT SC was about 3.2 times higher than the $\eta$ of the ARC SC. It demonstrates that the NT surface alleviates the loss of $\eta$ as $\theta$ increases compared to the planar ARC surface. Since the dimensions of nanotextures are increased in the bottom, the scattering effect becomes increasingly pronounced, and the incident photons are more likely to bounce back and forth among the NT surface. As a result, the optical path on the solar cell surface is prolonged, leading to enhanced absorption by the active region while $\theta$ is modified. Hence, the three-dimensional NT surface is distinguished from the planar ARC surface. It was found that NT SC has omnidirectionality.

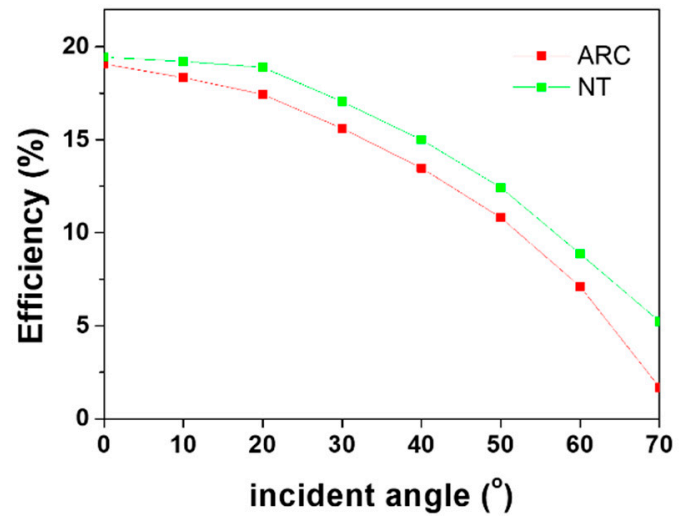

Figure 7. Efficiencies' dependence on $\theta$ for the bare surface SC, SC with SiNx ARC, and InAlP NT surface.

\section{Conclusions}

In conclusion, the planar ARC and NT InAlP window SC increase the light harvesting more than the bare surface SC, which was found from the suppressed reflectance, enhanced EQE spectra, and JSC. In particular, the NT surface decreases the reflectance and effects across the broad $\lambda$ range, containing the whole $\lambda$ spectrum of the GaAs 1 J SC. In addition, the NT SC was distinguished from the ARC SC by comparing the alleviated $\eta$ loss of the NT SC with the $\eta$ loss of the ARC SC as $\theta$ increased, which followed the purpose of this 
study to investigate the omnidirectionality of the NT surface on SCs. The presented concept and manufacturing technique are expected to benefit high-efficiency flexible SCs.

Author Contributions: Conceptualization, C.-W.K. and H.-J.K.; methodology of nanotexturing, C.-W.K. and H.-J.K.; fabricating the planar solar cell, G.-Y.P.; growing solar cells by MOCVD and H.-J.K.; calculation, J.-C.S.; investigation, C.-W.K.; writing-original draft preparation, C.-W.K.; writing-review and editing, H.-J.K.; supervision, H.-J.K.; funding acquisition, H.-J.K. All authors have read and agreed to the published version of the manuscript.

Funding: This research was supported by the Technology Development Program to Solve Climate Changes of the National Research Foundation (NRF) funded by the Ministry of Science ICT (2017M1A2A2048903), the Leading program of the National Research Foundation (NRF) funded by the Ministry of Science (2021M3H4A1A02051253), and Ministry of Trade, Industry and Energy (MOTIE) of the Republic of Korea (No. 70300026).

Institutional Review Board Statement: Not applicable.

Informed Consent Statement: Not applicable.

Conflicts of Interest: The authors declare no conflict of interest.

\section{References}

1. Takamoto, T.; Yamaguchi, M.; Taylor, S.J.; Yang, M.-J.; Ikeda, E.; Kurita, H. Radiation resistance of high-efficiency InGaP/GaAs tandem solar cells. Sol. Energy Mater. Sol. Cells 1999, 58, 265-276. [CrossRef]

2. Danilchenko, B.; Budnyk, A.; Shpinar, L.; Poplavskyy, D.; Zelensky, S.E.; Barnham, K.W.J.; Ekins-Daukes, N.J. 1 MeV electron irradiation influence on GaAs solar cell performance. Sol. Energy Mater. Sol. Cells 2008, 92, 1336-1340. [CrossRef]

3. Yamaguchi, M. Radiation-resistant solar cells for space use. Sol. Energy Mater. Sol. Cells 2001, 68, 31-53. [CrossRef]

4. Yamaguchi, M.; Okuda, T.; Taylor, S.J.; Takamoto, T. Superior radiation-resistant properties of InGaP/GaAs tandem solar cells. Appl. Phys. Lett. 1997, 70, 1566. [CrossRef]

5. Dharmarasu, N.; Yamaguchi, M.; Khan, A. High-radiation-resistant InGaP, InGaAsP, and InGaAs solar cells for multijuction solar cells. Appl. Phys. Lett. 2001, 79, 2399. [CrossRef]

6. Khan, A.; Marupaduga, S.; Anandakrishnan, S.S.; Alam, M. Radiation response analysis of wide-gap p-AlInGaP for superhighefficiency space photovoltaics. Appl. Phys. Lett. 2004, 85, 5218. [CrossRef]

7. Schubert, M.B.; Werner, J.H. Flexible solar cells for clothing. Materials 2006, 9, 42-50. [CrossRef]

8. Lee, Y.-H.; Kim, J.-S.; Noh, J.; Lee, I.; Kim, H.J.; Choi, S.; Seo, J.; Jeon, S.; Kim, T.-S.; Lee, J.-Y.; et al. Wearable textile battery rechargeable by solar energy. Nano Lett. 2013, 13, 5753-5761. [CrossRef] [PubMed]

9. Wen, Z.; Yeh, M.; Guo, H.; Wang, J.; Zi, Y.; Xu, W.; Deng, J.; Zhu, L.; Wang, X.; Hu, C.; et al. Self-powered textile for wearable electronics by hybridizing fiber-shaped nanogenerators, solar cells, and supercapacitors. Sci. Adv. 2016, 2, e1600097. [CrossRef]

10. Reb, L.K.; Bohmer, M.; Predeschly, B.; Grott, S.; Weindl, C.L.; Ivandekic, G.I.; Guo, R.; Dreibigacker, C.; Gernhauser, R.; Meyier, A.; et al. Perovskite and organic solar cells on a rocket flight. J. Joule 2020, 4, 1880-1892. [CrossRef]

11. Kishi, Y.; Inoue, H.; Murata, K.; Tanaka, H.; Kouzuma, S.; Morizane, M.; Fukuda, Y.; Nishiwaki, H.; Nakano, K.; Takeoka, A.; et al Ultralight flexible amorphous silicon solar cell and its application to an airplane. Sol. Energy Mater. 1991, 23, 312-318. [CrossRef]

12. Dhere, M.G.; Ghongadi, S.R.; Pandit, M.B.; Jahagirdar, A.H.; Scheiman, D. CIGS2 thin-film solar cells on flexible foils for space power. Prog. Photovolt. 2002, 10, 407-416. [CrossRef]

13. Zhao, J.; Green, M.A. Optimized antireflection coatings for high-efficiency silicon solar cells. IEEE Trans. Electron Devices 1991, 38, 1925-1934. [CrossRef]

14. Yin, Y.; Li, Z.; Kuo, H.; Lu, T. Efficiency improvement of single-junction InGaP solar cells fabricated by a novel micro-hole array surface texture process. J. Semicond. Sci. Technol. 2009, 24, 085007.

15. Yeh, L.; Tian, W.; Lai, K.; He, J. Exceptionally omnidirectional broadband light harvesting scheme for multi-junction concentrator solar cells achieved via ZnO nanoneedles. J. Sci. Rep. 2016, 6, 39134. [CrossRef]

16. Boden, S.A.; Bagnall, D.M. Optimization of moth-eye antirefection schemes for silicon solar cells. Prog. Photovolt. Res. Appl. 2010, 18, 195-203. [CrossRef]

17. Cai, J.; Qi, L. Recent advances in antirefective surfaces based on nanostructure arrays. Mater. Horiz. 2015, 2, 37-53. [CrossRef]

18. Allred, D.D.; Larsen, Z.; Muhlestein, J.; Turley, R.S.; Willey, A. Effective medium theory, rough surfaces, and Moth's eyes. J. Utah Acad. Sci. Arts Lett. 2009, 29, 273-286.

19. Yeh, L.; Lai, K.; Lin, G.; Fu, P.; Chang, H.; Lin, C.; He, J. Giant efficiency enhancement of GaAs solar cells with graded antirefection layers based on syringelike ZnO nanorod arrays. Adv. Energy Mater. 2011, 1, 506-510. [CrossRef]

20. Park, H.; Shin, D.; Kang, G.; Baek, S.; Kim, K.; Padilla, W.J. Broadband optical antirefection enhancement by integrating antirefective nanoislands with silicon nanoconical-frustum arrays. Adv. Mater. 2011, 23, 5796-5800. [CrossRef]

21. Sahoo, K.C.; Lin, M.; Chang, E.; Lu, Y.; Chen, C.; Huang, J.; Chang, C. Fabrication of antirefective sub-wavelength structures on silicon nitride using nano cluster mask for solar cell application. Nanoscale Res. Lett. 2009, 4, 680. [CrossRef] [PubMed] 
22. Chao, Y.C.; Chen, C.; Lin, C.; Dai, Y.; He, J. Antireflection effect of ZnO nanorods arrays. J. Mater. Chem. 2011, $20,8134-8138$. [CrossRef]

23. Photovoltaics Education. Available online: https://www.pveducation.org/pvcdrom/solar-cell-operation/quantum-efficiency (accessed on 5 December 2021). 